for women who might offer a potential risk within the range of our very limited knowledge.

Great care should be taken with each patient to determine the pattern of arterial incidents in the family history ; the past history of vascular episodes in the patient herself, including any event which might have represented cerebral arterial insufficiency even if it were never explained; a history of toxaemia of pregnancy, venous thrombosis, etc.; any past suggestion of hypertension; and any suggestion of hemiparetic migrainous attacks. We suggest that the presence of such events in the patient's history, many of which might be thought by some to be a reason for recommending the pill, should be regarded as a contraindication. If a patient taking an oral contraceptive begins to have episodes of loss of motor or sensory function corresponding to the supply of a cerebral artery, we would regard these as danger signals and would suggest that that method of contraception be discontinued from that day onwards. This is likely to affect only a very small number of the many thousands using oral contraceptives, and, even though the precaution may be unjustified in that particular patient, we are not yet sufficiently knowledgeable to be able to assess the danger with certainty, and it must surely be wiser to follow this course of action than to allow hemiplegia or aphasia to develop at the age of 25 .

\section{Summary}

Episodes of acute cerebral arterial insufficiency occurring in otherwise healthy women below the age of 45 have been studied before and after the introduction of oral contraceptives.

In the 10 years before 196425 such patients were seen in whom investigation showed no evidence of vascular anomalies, cardiac or renal disease, or hypertension.
In the three years 1964-6 the number of such cases referred was 25 . Eighteen of these 25 patients had been taking one or other of the oral contraceptives.

Publicity regarding side-effects of the pill, local knowledge of our interest, and increasing awareness of the type of case needing full investigation may all have caused misleading inflation of these figures, but it is suggested that there is an apparent association between the use of oral contraceptives and the increased number of episodes of cerebral arterial insufficiency that cannot be disregarded, and certain factors are discussed which in the light of present knowledge might contraindicate their use or warrant their discontinuation in individual patients.

We wish to thank our colleagues, Mr. J. M. Small and Dr. I. A. Guest, for allowing one of us to see two patients originally admitted under their care, and the many physicians and general practitioners in the Birmingham region who have referred the other cases over the past 13 years.

\section{REFERENCES}

Bickerstaff, E. R. (1964). Brit. med. f., 2, 82.

Brit. med. Ұ., 1964, 2, 38.

Caspary, E. A., and Peberdy, M. (1965). Lancet, 1, 1142

Ehtishamuddin, M. (1965). Brit. med. Ұ., 1, 921.

Illis, L., Kocen, R. S., McDonald, W. I., and Mondkar, V. P. (1965). Ibid., 2, 1164.

Keen, H., Rose, G., Pyke, D. A., Boyns, D., Chlouverakis, C., and Mistry, S. (1965). Lancet, $2,505$.

Nevin, N. C., Elmes, P. C., and Weaver, J. A. (1965). Brit. med. Y., 1, 1586 .

Whitty, C. W. M., Hockaday, J. M., and Whitty, M. M. (1966). Lancet, 1,856

Winter, I. C. (1965). Metabolism, 14, 422

Wynn, V., and Doar, J. W. H. (1966). Lancet, 2, 715.



\title{
Treatment of Childhood Depression with Antidepressant Drugs
}

\author{
EVA A. FROMMER,* M.B., B.S., D.C.H., D.P.M.
}

Brit. med. Y., 1967, 1, 729-732

Depressive illness in childhood is probably much commoner than is generally realized. The presenting symptoms may be deceptive and misleading, as they often appear to be physical rather than psychological in origin; or else an alteration in personality in the child is mistakenly attributed to a failure to pull himself together and unwillingness to accept advice and help.

Depression should be suspected in children who complain of non-specific recurrent abdominal pain, headache, sleep difficulties and irrational fears, or mood disturbances such as irritability, unaccountable tearfulness, and associated outbursts of temper. Such children often develop sudden difficulty in social adjustments, which previously were normal ; they may either withdraw themselves from the family circle and former friends or display outright aggressive and antisocial behaviour (Frieze, 1965). There is often apparently inexplicable failure at school ; this causes further misery if it is attributed to a lack of effort, and the underlying depressive illness remains unrecognized. Such symptoms tend to be dismissed as "functional" or classed as a "behaviour disorder," and phenobarbitone is commonly prescribed as a general sedative. From the psychiitric point of view the emphasis so far has been on treating the

-er and her relation to the child, rather than the depressive

-in-charge, Child Psychiatric Clinic, St. Thomas's Hospital, E.1. illness of the child himself, though, as this paper shows, it is often a depressive illness that lies at the root of the difficulties in the mother-child relations.

Because of the success of antidepressant drugs in depressed and anxious adults of good previous personality with very similar symptoms (Sargant and Dally, 1962), and the promising results observed in a pilot study in children, a comparison of the effects of phenobarbitone against a combination of phenelzine (Nardil) and chlordiazepoxide (Librium) was made in a group of children whose symptoms were thought to be depressive in origin. Forty-one children (17 boys, 24 girls) out of more than 200 seen in the child-psychiatry clinic at St. Thomas's Hospital during the 15 months while the trial was in progress were originally included in this study, and fortunately no fewer than 32 completed it.

\section{The Children}

The age range of the children was 9 to 15 years; puberty had come early to a few, but the majority were still prepubertal and physically immature. Two distinct clinical groups emerged, which for convenience are here termed the "phobic" group and the "mood disorder" group (Table I).

The children in the phobic group were generally afraid of parting from their mother or going out of the house, and 
particularly of going to school. They were usually conscientious children who could not overcome their anxiety, slept badly, had tension symptoms, and were failing at school because

TABLE I.-Comparison of Symptoms Occurring in the Two Groups (One Patient Who Could Not be Classified in Either Group is Not
Included)

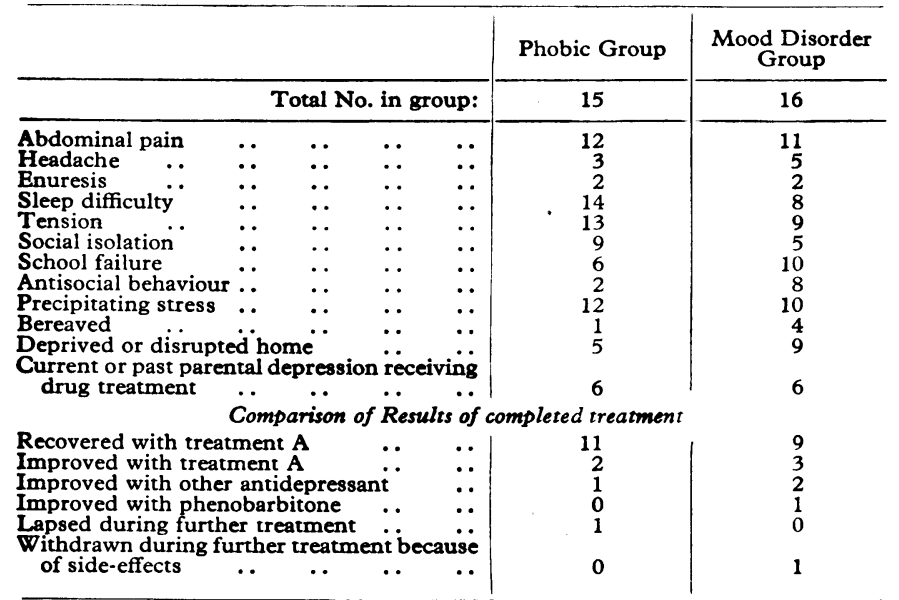

of frequent absences. They tended to look sullen or blankly expressionless, rarely showed a frankly depressive picture or its typical mood disorder, and sometimes even denied any feeling of depression.

The children in the mood disorder group had more obviously depressive symptoms. They were weepy, irritable, had temper outbursts, and some displayed quite serious antisocial behaviour. A few complained of actually feeling depressed, and one boy had made suicidal threats. More came from emotionally deprived homes or had been upset by death or loss in other ways of one or both parents.

Nevertheless, the two groups had a good deal in common. In the trial described below breaking of the code showed no significant difference between them in response to treatment $\mathrm{A}$ or treatment $\mathrm{B}$, and there was no difference to speak of in response to the more prolonged treatment which followed the trial, as shown in Table I. Moreover, in both groups the majority of the children had abdor.ninal pain as a prominent symptom, and several had headaches which were persistent and very troublesome.

The initial onset of the depression and anxiety had often been related to a precipitating stress; typically these were the death or permanent departure from home of a parent or close relative, hospitalization, moving house, or a change of school. Where a precipitating cause existed it seemed to involve a separation experience for the child, sometimes associated with the added stress of physical trauma, as after an accident, an operation, or in one case repeated lumbar puncture for suspected meningitis, It appeared as though the depressive pattern once established by such events could not subsequently be broken without great difficulty. The duration of illness varied from three months to over five years, and in most was over one year. In several cases a recent exacerbation of the symptoms had finally brought about their attendance at the clinic.

\section{Clinical Trial}

A double-blind cross-over trial was designed. Phenelzine and chlordiazepoxide (treatment A) was compared with phenobarbitone given with an inert placebo (treatment B) in each child. The usual dose of phenelzine was $15 \mathrm{mg}$. b.d., chlordiazepoxide $10 \mathrm{mg}$. b.d., and phenobarbitone $30 \mathrm{mg}$. b.d. For bigger and older children the dose of phenelzine was $15 \mathrm{mg}$. t.d.s., and $30 \mathrm{mg}$. phenobarbitone t.d.s. was also used. Instructions were given to reduce the red tablets (whether phenelzine or phenobarbitone) if the child became obviously giddy; this happened in one case where phenelzine $15 \mathrm{mg}$. and phenobarbitone $30 \mathrm{mg}$. were given daily. The tablets and capsules of treatment A exactly resembled those of treatment B, and neither patient nor doctor knew which was being given. Each treatment was given for a period of two weeks, the order of administration depending on the hospital pharmacists. The parents' co-operation was obtained and the usual warnings regarding possible side-effects and dietary restrictions were given. Most children were seen by me weekly, and some fortnightly, with one or both parents, and I assessed them according to the parents' reports and to clinical examination. For the purpose of the trial, the state at the end of the first fortnight was compared with the state initially, and at the end of the second fortnight the state was compared, not with the initial state, but with that at the end of the first fortnight. Change in state was assessed as " improved" $(++)$, "slightly improved " $(+)$, " unchanged " $(0)$, or " worse " $(-)$.

While two weeks is a short time in which to be certain about the antidepressant effects of these drugs, the pilot study had shown some lightening of mood in depressed children, of ten as early as the first week of treatment with phenelzine and chlordiazepoxide. It was anticipated that most of the children would require further treatment after the trial was completed.

\section{Results}

Sixteen children were classified as suffering from mood disorder, 15 were regarded as phobic, and one child was unclassifiable. With two assessments of the degree of improvement made on each subject, the scores were distributed as shown in Table II. Though the phobic cases did perhaps slightly better than the others, the difference is slight and not significant. With this in mind, the two clinical groups were merged for the purpose of any further comparisons, and the unclassified case was added to them.

It is not surprising that the treatment given first had significantly better results than the second treatment, for even a placebo is likely to have some good effect, and after any improvement a return to status quo is recorded as worse, and maintained improvement as no change; hence the figures of Table III.

\begin{tabular}{|c|c|c|c|c|c|c|c|}
\hline \multicolumn{3}{|c|}{ Degree of improvement: } & \multirow{2}{*}{$\frac{++}{13}$} & \multirow{2}{*}{$\frac{+}{10}$} & \multirow{2}{*}{$\begin{array}{l}0 \\
3 \\
5\end{array}$} & \multirow{2}{*}{$\frac{-}{10}$} & \multirow{2}{*}{$\begin{array}{c}\text { Tota) } \\
\begin{array}{l}32 \\
30\end{array}\end{array}$} \\
\hline $\begin{array}{l}\text { Mood cases.. } \\
\text { Phobic cases }\end{array}$ & $\ldots$ & $\because$ & & & & & \\
\hline
\end{tabular}

TABLB III

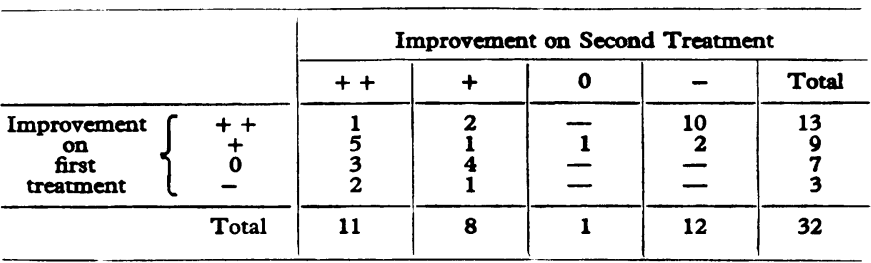

The relation between result gained and order in which treatment was given could be clearly shown by classifying individual patients according to correlated findings. However, on examining the results it was found that of the large number of 12 patients showing worse with the second treatment nine had been given treatment $A$ in the first fortnight and only three treatment $B$. By far the bigger difference, in fact, was between treatments and not between orders of treatment.

The results of the two treatments, classified by the stage at which they were given, are shown in Table IV. From this it . would appear that treatment $A$ is equally effective given fir second ; treatment $B$ produces some improvement if giv but as a rule a definite worsening if it follows tre 
All the eight children who improved ++ after a first fortnight on $\mathrm{A}$ were worse after the second fortnight on $\mathrm{B}$; of the five children who improved ++ after a first fortnight on $B$ one at the end of a second fortnight on $\mathrm{A}$ had made a further ++ improvement, two had improved + , and two were worse.

The results of the trial show that $A$ is a significantly better treatment than $\mathrm{B}$; comparing all $\mathrm{A}$ results against all $\mathrm{B}$ results, and grouping together the + and 0 figures, $\chi^{2}$ is equal to 10.26, which is significant at 0.01 confidence limits.

TABLE IV

\begin{tabular}{c|c|c|c|c}
\hline \multirow{2}{*}{$\begin{array}{c}\text { Degree of } \\
\text { Improvement }\end{array}$} & \multicolumn{2}{|c|}{ Treatment A Given } & \multicolumn{2}{c}{ Treatment B Given } \\
\cline { 2 - 5 } \cline { 4 - 5 } & First & Second & First & Second \\
\hline++ & 8 & 10 & 5 & 1 \\
+ & 3 & 4 & 6 & 4 \\
- & 3 & $\frac{4}{2}$ & 2 & 9 \\
\hline Total .. & 1 & 17 & 17 & 15 \\
\hline
\end{tabular}

\section{Post-trial Period}

Table $\mathrm{V}$ shows the further progress of the 32 children who completed the trial. Of the 24 who responded best to phenelzine and chlordiazepoxide three were well after only the two weeks' antidepressant treatment during the trial, and 16 more continued to improve on further treatment with the same drugs. Three others did better when the medication was changed to other antidepressants, one felt better on phenobarbitone, and one lapsed from further treatment.

TABLE V.-Results of Further Treatment After Completion of the Trial

\begin{tabular}{|c|c|c|c|}
\hline & $\begin{array}{c}\text { Children } \\
\text { Responding } \\
\text { to Treatment A }\end{array}$ & $\begin{array}{c}\text { Children } \\
\text { Responding } \\
\text { to Treatment B }\end{array}$ & Total \\
\hline $\begin{array}{l}\text { Improved with further A treatment } \\
\text { Improved with further B treatment } \\
\text { Requiring no further treatment } . . \\
\text { Requiring other ancidepressants ... } \\
\text { Lapsed } \\
\text { Withdrawn from treatment A on } \\
\text { medical grounds though showing } \\
\text { improvement } \quad . .\end{array}$ & $\begin{array}{r}16 \\
1 \\
3 \\
3 \\
1\end{array}$ & $\begin{array}{l}6 \\
0 \\
0 \\
0 \\
1\end{array}$ & $\begin{array}{r}22 \\
1 \\
3 \\
3 \\
2\end{array}$ \\
\hline Total .. & 24 & 8 & 32 \\
\hline
\end{tabular}

Of the eight children who had responded better to phenobarbitone seven improved still further subsequently on treatment with phenelzine and chlordiazepoxide, but one of these developed fainting attacks, possibly due to postural hypotension, and treatment was discontinued; one other child lapsed from further treatment.

Most of the children needed two to four months' further treatment, but only one more than six months; in some the drug dosages were reduced during this period. Of the 32 children no fewer than 20 finally made a good recovery, five improved considerably on phenelzine and chlordiazepoxide, and three improved further when changed to amitriptyline. Thus altogether 28 improved on antidepressants. Only one patient showed convincing improvement on phenobarbitone. Several parents said that their real child had at last been restored to them after months or years of illness.

The existence of previously good behaviour, a past precipitating cause, and a supportive family background were important factors for recovery.

Children Who Failed to Complete the Trial.-Three girls who had to be withdrawn from the trial because of hysterical behaviour were found to have been receiving phenelzine and chlordiazepoxide. The reaction developed within the first days of treatment. Six other children failed to continue the trial for various reasons, but four of these had in fact shown some improvement while receiving what turned out to be phenelzine and chlordiazepoxide when the code was broken at the end of the trial.

\section{Discussion}

Very little work has been done on the treatment of depressive illness in childhood with the monoamine oxidase inhibitors such as phenelzine. Most work on the use of antidepressants in children has been confined to studying amitriptyline or imipramine (Poussaint and Ditman, 1965) in relation to the control of enuresis. Connell (1965), however, mentions the use of phenelzine in the treatment of suicidal depressions in children, and Reca de Acosta et al. (1959), discussing the use of the monoamine oxidase inhibitor nialamide in mentally retarded children, described notable improvement in 33 out of 37 of them, and a dramatic response in two more whose I.Q. had not reflected their true potential. Some of the children in the present series showed a similar type of change on recovery.

Since the present study gratifying results have continued to be obtained in this clinic both with phenelzine and with another monoamine oxidase inhibitor, isocarboxazid (Marplan), and, in all, over 100 children have been treated with these drugs. Chlordiazepoxide has been used in combination with these antidepressants in most cases. It is a useful adjunct, as its tranquillizing and disinhibiting effect offers early relief from the tension and anxiety which are a part of the depressive picture in so many. On clinical testing it does not seem to have any antidepressant action by itself, and may even aggravate depression in certain cases if given alone. On the other hand, the monoamine oxidase inhibitors cause a profound change in the depressed child's mood and attitude to life. Sargant and Dally (1962) found that adult patients with depression on these combined drugs relapse if phenelzine is withdrawn and only chlordiazepoxide continued as the maintenance drug, but not vice versa.

The partial improvement of some children while they were on phenobarbitone during the trial could easily have been regarded as satisfactory in a clinical setting. It was the doubleblind cross-over technique that showed how much better they in fact did on modern antidepressants.

Precautions must of course be taken, especially when prescribing monoamine oxidase inhibitors for children who have inadequate parental supervision. In the present series significant side-effects were encountered in only one case-the girl with the fainting attacks-and her mother had reacted similarly to antidepressant drugs. However, some children do become worse during the first few days after the start of treatment and three had to be withdrawn from the present trial because of this. Such a reaction can usually be met by adjusting the dose of drugs, but sometimes a change to an antidepressant of another group, such as imipramine or amitriptyline, is needed.

West and Dally (1959) have shown that two groups are found among depressed adults which closely resemble the two groups into which most of the present series of children fall (Table I) In adults it was found that the phobic, anxious, and depressed patients responded best to treatment with monoamine oxidase inhibitors. Further research on this grouping in children and its significance is planned.

Over a third of the children in this series had a parent with a concurrent or past depressive illness which required treatment with antidepressant drugs (Table I). Drugs of the same group of ten proved effective in both parent and child, confirming again the findings first suggested by Pare, Rees, and Sainsbury (1962) in the case of close adult relatives with depressive illnesses. Frieze (1965) mentions a high incidence of parental depression in the families of depressed children. All these findings suggest that the illness in the child may well have a constitutional basis.

So far nothing has suggested that the depressive illnesses described here always eventually lift spontaneously or that the children will "grow out" of them. Some children may be permanently scarred by non-recognition of these illnesses. It was disturbing to find such a high incidence of prolonged 
yet recoverable illness-in 30 children of the original 41 this had lasted for over a year, and in no fewer than eight of them for over five years. It was even more disturbing to find how long their depression had gone undetected, often despite repeated clinical examinations. As these symptoms are fairly common among children of school age, there may well be a sizable group with a handicapping yet treatable depressive illness in the school population. A personality change in a child is too easily attributed to "growing up," and it is too readily assumed that the attention which his difficulties attract, whether aches and pains or behaviour disorders, affords him sufficient gratification. Yet once they had recovered with treatment these children were delighted to be well, and showed no regret for any lost parental attention to vanished symptoms.

In conclusion it appears plain that, despite the limitations and inaccuracies which inevitably accompany an outpatient drug trial such as this, antidepressant drugs are much more useful for the treatment of depressed children, whether with "functional " somatic symptoms or a "behaviour disorder," than is the phenobarbitone so often used.

Much more work is needed to clarify the clinical picture of depressive illnesses seen in childhood, and to differentiate and improve this technique of treatment; but the results in this preliminary study far exceeded expectations, and suggest that such further research will be well worth while.

\section{Summary}

The clinical symptoms of childhood depression are described. A double-blind cross-over trial showed that phenelzine and chlordiazepoxide are superior to phenobarbitone and an inert capsule in treating these childhood depressions. This finding was confirmed during further periods of clinical treatment. Many children recovered rapidly from illnesses of up to five years' duration, and the diagnosis had often been missed.

My thanks are due to Dr. Eliot Slater for his help and advice in the interpretation of the results, and to $m y$ colleagues in the departments of paediatrics and psychological medicine, who referred patients and helped me with this work.

\section{REFERENCES}

Connell, P. (1965). In Modern Perspectives in Child Psychiatry, edited by J. G. Howells, p. 421. London.

Frieze, M. (1965). Brit. med. ๆ., 2, 1489.

Pare, C. M. B., Rees, L., and Sainsbury, M. J. (1962). Lancet, 2, 1340. Poussaint, A. F., and Ditman, K. S. (1965). F. Pediat., 67, 283.

Reca de Acosta, T., Moreno de Taubenslag, I., and Kusnir, J. E. (1959). f. Soc. Ciénc. méd. Lisboa, 123, Suppl. p. 270.

Sargant, W., and Dally, P. (1962). Brit. med. Y., 1, 6.

West, E. D., and Dally, P. J. (1959). Ibid., 1, 1491.

\title{
Trial of Ascorbic Acid in Senile Purpura and Sublingual Haemorrhages
}

\author{
G. ARTHUR,* M.B., CH.B.; J. A. MONRO, † M.B., B.S.; P. POORE, $\ddagger$ M.B., B.S.; W. B. RILWAN,§ M.B., B.S. \\ E. LA C. MURPHY, M.A., M.D., D.P.H.
}

Brit. med. F., 1967, 1, 732-733

Taylor (1965) noted that sublingual haemorrhages and purpuric lestons of the skin were common in elderly patients under his care, and after preliminary investigations put forward the hypothesis that these were manifestations of scurvy.

Hitherto, work such as that by Tattersall and Seville (1950) had been interpreted as meaning that senile purpura is not a manifestation of deficiency of vitamin C, and Andrews and Brook (1966) have reported no improvement in either sublingual haemorrhages or senile purpura on feeding supplements of ascorbic acid. They did, however, observe in their cases of sublingual haemorrhage (but not of purpura) a lower level of vitamin $C$ in white cells. A fairly long feeding trial with substantial amounts of ascorbic acid, as reported below, should therefore be of interest in helping to elucidate the cause of both conditions.

\section{Method}

As a first step Dr. Taylor was asked to demonstrate to the medical staff in the seven hospitals participating in the tests the purpuric and sublingual lesions which he regarded as manifestations of a scorbutic or subscorbutic state. (Figs. 1 and 2 illustrate examples.)

From the geriatric wards of seven hospitals 94 long-stay patients with lesions were selected for the trial in March 1966, but because of discharges and deaths only 77 remained at the end of the experiment; of these, 73 had senile purpura and 40 had petechial tongue lesions, 36 having both. Diagrams were drawn and descriptive notes made of the distribution and magnitude of lesions on the forearms and hands and also on the tongues at the beginning of the trial, and after intervals of two weeks, one month, and six weeks. Photographs were taken at the beginning and end of the trial (except in two hospitals where this proved impracticable). No patients with rheumatoid arthritis, diabetes mellitus, carcinoma, or any blood dyscrasia were included in the trial, nor any on supplements of vitamin C. The nursing staff were warned of the importance

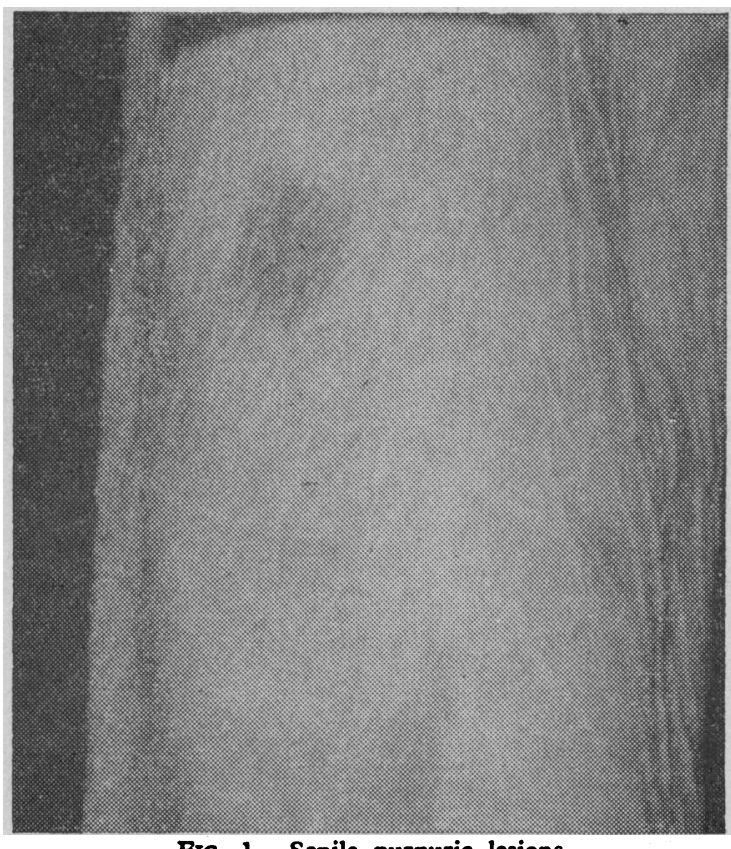

FIG. 1.-Senile purpuric lesions. 